\title{
Proprioceptive accuracy is not associated with self-reported body awareness, body competence, and affect
}

\author{
Á Horváth ${ }^{1,2}$, E Ferentzi ${ }^{2}$, F Köteles ${ }^{2}$ \\ ${ }^{1}$ Doctoral School of Psychology, ELTE Eötvös Loránd University, Budapest, Hungary \\ ${ }^{2}$ Institute of Health Promotion and Sport Sciences, ELTE Eötvös Loránd University, Budapest, Hungary
}

Received: May 12, 2019

Accepted: October 14, 2019

\begin{abstract}
Purpose: Proprioception plays an essential role in motor control and in psychological functioning: it is the basis of body schema and the feeling of body ownership. There are individual differences in the processing accuracy of proprioceptive stimuli. Although proprioceptive acuity plays an important role in physical competence, there are contradictory findings concerning the role it plays in healthy psychological functioning. This study aims to shed more light on this association. Material and methods: Sixty-eight young adults participated in this study. We estimated proprioceptive acuity by the reposition accuracy of elbow joint positions. We tested both dominant and non-dominant hands with two different versions of Joint Position Reproduction Test. Perceived physical competence, body awareness, and affectivity were assessed using questionnaires (Physical Competence scale of Body Consciousness Questionnaire, Somatic Absorption Scale, and Positive and Negative Affectivity Schedule, respectively). Results: No significant association between proprioceptive acuity and body awareness, perceived body competence, and positive and negative affect was found. Conclusion: Proprioceptive acuity, measured in the elbow joint, does not play a substantial role in body awareness, perceived body competence, and affect.
\end{abstract}

Keywords: proprioception, proprioceptive accuracy, physical competence, body awareness, affect

\section{Introduction}

Based on our proprioceptive sense, we are able to assess the relative position of our body parts, our posture, and the tightness of our muscles, even in the absence of visual stimuli (36). This ability relies on signals coming from mechanoreceptors located in the muscles (muscle spindles), tendons (Golgi organs), ligaments, and skin (27). Beyond the aforementioned static sensations, proprioception plays an essential role in motor control. It provides the central nervous system with afferent information about the actual position and state of various parts of the sensorimotor system, which helps it to maintain muscle tone, body posture, and seamless movements to achieve the desired state (26).

The majority of the aforementioned processes is automatic and does not require attention or conscious effort. To some extent, we are also able to sense the position of

Corresponding author: Áron Horváth

Doctoral School of Psychology, ELTE Eötvös Loránd University

Bogdánffy Ödön u. 10, 1117 Budapest, Hungary

Phone: +36 20422 0969; Fax: +36 12090 619; E-mail: horvath.aron@ppk.elte.hu

This is an open-access article distributed under the terms of the Creative Commons Attribution 4.0 International License, which permits unrestricted use, distribution, and reproduction in any medium, provided the original author and source are credited, a link to the CC License is provided, and changes - if any - are indicated. (SID_1) 
joints and muscle tone consciously (7); however, there are considerable individual differences in the processing of proprioceptive stimuli, for example, with respect to its accuracy (13).

A number of methods have been developed to measure various aspects of proprioceptive acuity or accuracy. Concerning the position of the joints, one of the most widely used tests is the Joint Position Reproduction Test (8). In this test, the task of the participants is the reproduction of the target position of a given body segment without visual feedback. The test starts with placing the reference body part from starting position into the target position. Later, in ipsilateral condition, the body part is moved back into the starting position, and the participant is asked to reproduce the target position with the same limb. In contralateral condition, however, the reference limb stays in the target position, and the reproduction occurs with the contralateral limb (8).

Proprioceptive acuity plays an important role in various aspects of physical competence. For example, it is associated with higher level of sport performance $(11,14)$, and reversely associated with the number of sport injuries $(4,12,24,25)$. Beyond motor control, proprioception also impacts psychological functioning. One of the first steps in the development of the self is the differentiation between the body and the environment. In this progression, it is fundamental to implement and recognize self-generated movements (16). This is possible by comparing proprioceptive afferent signals with corollary discharge, which is the predicted state of the body based on the efferent copy of motor command $(21,42)$. Proprioception yields the basis of body schema, which is a complex representation of the body that operates mainly on a not conscious level, and gives rise to motor control and cognition (7). Proprioceptive information may also play a role in the formation of emotions. For example, muscle tone increases in stressful situations (20), and the systematic relaxation of the muscles can in turn reduce anxiety (29).

A number of studies demonstrate the positive association between proprioceptive processing and healthy psychological functioning. Worse than average acuity is associated with schizophrenia $(5,33,34)$ and fibromyalgia (2). Higher acuity is not always associated with positive conditions, however; for example, somatoform patients are more precise than healthy controls when they have to judge their muscle tone (35). There are also studies that report no association between proprioceptive processing and the severity of subclinical or clinical mental illnesses $(1,19,28$, $31,32,38)$.

Theoretically, consciously accessible proprioceptive abilities, for example, physical performance or the perception of the position of the body and its parts might interact with and contribute to the self-concept in multiple ways. First, those with higher levels of dispositional body-focused attention (also known as body awareness) might realize and correct errors between expected and actual body positions more readily, which leads to higher proprioceptive accuracy over time. Second, proprioceptive accuracy contributes to better physical performance and perceived body competence. Finally, the latter positively affects self-esteem (37), which is associated with higher levels of positive affect and lower levels of negative affect $(40,41)$.

This study aims to assess the assumed associations between proprioceptive accuracy and high-level psychological constructs. It was expected that proprioceptive accuracy is positively associated with body awareness $(H 1)$, perceived body competence $(H 2)$, and positive affect $(H 3)$, and reversely associated with negative affect $(H 4)$. 


\section{Materials and Methods}

\section{Participants}

A priori power analysis for a medium-level association $(r=0.3$, one-tailed, $\alpha=0.05$, and $1-\beta=0.80$ ) indicated $n=67$ as minimum necessary sample size (G*Power v3.1.9.2) (6). Participants of the study were undergraduate university students $(n=68$, age: $21.1 \pm 1.49$ years, $52.9 \%$ female, $92 \%$ right-handed); they participated in the study for partial course credit. Most of them attend in regular (although not elite level) sport activity; they spent $9 \pm 5.014 \mathrm{~h}$ a week with sport training in average. The study was approved by the Research Ethics Committee of the university; all participants signed informed consent forms before participation.

\section{Questionnaires}

To assess body awareness, participants filled out the Somatic Absorption Scale (SAS) (18). The questionnaire was developed to measure non-pathological tendency to monitor body processes. It contains 19 items, for example, "When I watch TV or a movie, I am very aware of my bodily reactions." Two out of 19 items are reversed. Participants have to rate statements on a 5-point Likert scale. Higher final scores on the scale indicate higher levels of bodily awareness. In this study, Cronbach's $\alpha$ value was 0.794 , showing adequate internal consistency.

Body competence was measured by the Physical Competence subscale of the Body Consciousness Questionnaire (BCQ-PC) (22). This scale consists of four questions concerning various aspects of perceived physical competence, for example: "I'm better coordinated than most people." Higher values mean higher levels of perceived competence. Internal reliability, measured by Cronbach's $\alpha$, was sufficient, with a value of 0.779 .

Positive and Negative Affectivity Schedule (PANAS) (9) was used to measure affect. This questionnaire was developed to measure the current (state) or general (trait) emotional state of a person. We used trait instruction in this study. The questionnaire consists of 10 items to measure positive affect, e.g., enthusiasm, and 10 items to measure negative affect, e.g., nervousness. Participants have to rate how often they feel the given emotional state on a 5-point Likert scale. Higher total scores refer to higher levels of positive and negative affect, respectively. Cronbach's $\alpha$ of the positive scale was 0.876 and the negative scale was 0.920 in this study, both indicating a high level of internal consistency.

\section{Proprioceptive measurements}

We used the Joint Position Reproduction Test (8) to measure proprioceptive acuity. We measured the position of the elbow joint, and tested both dominant and non-dominant hands of the participants with the two above-described versions (i.e., ipsilateral and contralateral conditions) of the test. Overall, four tests (each with five trials) were performed: ipsilateral dominant (ID), ipsilateral subdominant (IS), contralateral dominant (CD), and contralateral subdominant (CS). In each case, participants were in a seated position with the elbow placed on a rotatable board at shoulder height, with eyes closed and covered. Before each trial, the arm of the participant was fully stretched (starting position), then it was moved to the target position. In ipsilateral condition, the arm was moved back to the starting position, and the participant's task was to reproduce the target 
position by actively moving the same arm. In contralateral condition, the reference arm stayed in the target position, and the reproduction happened with the contralateral arm. We used 5 target positions: $150^{\circ}, 120^{\circ}, 90^{\circ}, 60^{\circ}$, and $30^{\circ}$. The positions were presented in a random order. We could measure the position of the elbow joint with a precision of $\pm 1^{\circ}$. Proprioceptive accuracy in each test was calculated as the absolute value of the average difference between the degree of the target and reproduced position; higher scores refer to lower levels of accuracy. Internal consistency was in the acceptable domain (i.e., Cronbach's $\alpha$ above 0.65 ) for two tests out of four (ID: 0.557, IS: 0.677, CD: 0.659, CS: 0.603).

\section{Procedure}

Participants filled out the Hungarian versions of the questionnaires online at home, on the day before the proprioception measurements the latest. The order of the questionnaires was the same for every person, i.e., PANAS, SAS, and BCQ-PC. The assessment of proprioceptive acuity was conducted in the laboratory of the university. Participants were asked to wear comfortable clothes, not to conduct hard physical exercise, and avoid the use of any psychoactive drugs, including caffeine and alcohol $12 \mathrm{~h}$ before the experiment. We randomized the order of the four proprioceptive measurements to avoid the effect of learning or fatigue. Participants were seated in a chair with adjustable height. We could also adjust the length of the rotatable board to achieve a standard position for the Joint Position Reproduction Test: upper arms were parallel with the ground and with the line of the upper body. During the task, only the elbow joint moved.

\section{Statistical analyses}

Statistical analysis was conducted using the JASP v0.9.0.1 software (15). As the Shapiro-Wilk test indicated significant deviation from normality for several variables, hypotheses were tested using the Spearman's correlation. As direction of associations was inherent part of our hypotheses, one-tailed significance tests were used. To avoid inflation of type 1 error due to a high number of independent analyses, the accepted level of significance was set to $0.05 / 16=0.003$ (Bonferroni correction). Beyond the widely used frequentist method, we also used the Bayesian approach to evaluate our hypotheses. In Bayesian statistics, the probability of an alternative hypothesis compared to the null hypothesis is calculated; thus, the major caveats of the frequentist statistics (e.g., issues with types I and II error) can be avoided. If the so-called Bayes factor $\left(\mathrm{BF}_{10}\right)$ is smaller than 1 , the null hypothesis is more probable than the alternative hypothesis (17).

\section{Results and Discussion}

Results

Descriptive statistics of the assessed variables are presented in Table I.

Frequentist correlation analyses revealed no significant correlation between proprioceptive error and any of the assessed psychological constructs (for details, see Table II).

Bayesian analysis supported this conclusion, as all $\mathrm{BF}_{10}$ values are below 1 (Tables II and III). 
Table I. Descriptive statistics of the assessed variables

\begin{tabular}{|l|c|c|c|}
\hline Variable & Mean \pm SD & Minimum & Maximum \\
\hline $\begin{array}{l}\text { Proprioceptive error (ipsilateral } \\
\text { dominant) }\end{array}$ & $6.40 \pm 3.794$ & 0.00 & 19.00 \\
\hline $\begin{array}{l}\text { Proprioceptive error (ipsilateral } \\
\text { subdominant) }\end{array}$ & $5.13 \pm 4.359$ & 0.00 & 17.00 \\
\hline $\begin{array}{l}\text { Proprioceptive error (contralateral } \\
\text { dominant) }\end{array}$ & $5.71 \pm 3.758$ & 0.00 & 12.00 \\
\hline $\begin{array}{l}\text { Proprioceptive error (contralateral } \\
\text { subdominant) }\end{array}$ & $5.34 \pm 3.454$ & 0.00 & 86.00 \\
\hline Body awareness (SAS) & $61.62 \pm 8.513$ & 45.00 & 20.00 \\
\hline Body competence (BCQ-PC) & $14.51 \pm 3.005$ & 9.00 & 50.00 \\
\hline Positive affect (PANAS-P) & $37.09 \pm 6.093$ & 18.00 & 38.00 \\
\hline Negative affect (PANAS-N) & $18.82 \pm 7.461$ & 10.00 & \\
\hline
\end{tabular}

For proprioceptive error, higher values refer to lower levels of acuity. SAS: Somatic Absorption Scale; BCQ-PC: Body Consciousness Scale - Physical Competence Subscale; PANAS-P: Positive and Negative Affectivity Schedule Positive Affectivity subscale; PANAS-N Positive and Negative Affectivity Schedule - Negative Affectivity subscale

Table II. Correlations (Spearman's $\rho$ coefficients) between variables: frequentist approach

\begin{tabular}{|l|c|c|c|c|}
\hline & $\begin{array}{c}\text { Proprioceptive } \\
\text { error (ipsilateral } \\
\text { dominant) }\end{array}$ & $\begin{array}{c}\text { Proprioceptive } \\
\text { error (ipsilateral } \\
\text { subdominant) }\end{array}$ & $\begin{array}{c}\text { Proprioceptive } \\
\text { error (contralateral } \\
\text { dominant) }\end{array}$ & $\begin{array}{c}\text { Proprioceptive } \\
\text { error (contralateral } \\
\text { subdominant) }\end{array}$ \\
\hline $\begin{array}{c}\text { Body awareness } \\
\text { (SAS) }\end{array}$ & $-0.069 ; p=0.287$ & $0.031 ; p=0.600$ & $0.002 ; p=0.506$ & $0.020 ; p=0.564$ \\
\hline $\begin{array}{c}\text { Body competence } \\
\text { (BCQ-PC) }\end{array}$ & $0.139 ; p=0.870$ & $0.080 ; p=0.739$ & $0.055 ; p=0.673$ & $-0.051 ; p=0.341$ \\
\hline $\begin{array}{c}\text { Positive affect } \\
\text { (PANAS-P) }\end{array}$ & $0.026 ; p=0.582$ & $-0.072 ; p=0.282$ & $0.027 ; p=0.587$ & $0.000 ; p=0.500$ \\
\hline $\begin{array}{c}\text { Negative affect } \\
\text { (PANAS-N) }\end{array}$ & $-0.019 ; p=0.561$ & $0.268 ; p=0.014$ & $0.075 ; p=0.271$ & $-0.097 ; p=0.784$ \\
\hline
\end{tabular}

One-tailed significance, Bonferroni-corrected level of significance is 0.003. SAS: Somatic Absorption Scale; BCQPC: Body Consciousness Scale - Physical Competence subscale; PANAS-P: Positive and Negative Affectivity Schedule - Positive Affectivity subscale; PANAS-N Positive and Negative Affectivity Schedule - Negative Affectivity subscale

\section{Discussion}

Contrary our hypotheses, no association was found between indicators of proprioceptive acuity with respect to the elbow joint and perceived body awareness $(H 1)$, body competence (H2), and positive and negative affect ( $H 3$ and $H 4$, respectively).

We hypothesized that a higher level of dispositional body awareness leads to greater attention to proprioceptive signals, which is associated with higher proprioceptive accuracy. 
Table III. Correlations (Kendall's $\tau$ coefficients) between variables: Bayesian approach

\begin{tabular}{|c|c|c|c|c|}
\hline & $\begin{array}{c}\text { Proprioceptive } \\
\text { error (ipsilateral } \\
\text { dominant) }\end{array}$ & $\begin{array}{c}\text { Proprioceptive } \\
\text { error (ipsilateral } \\
\text { subdominant) }\end{array}$ & $\begin{array}{c}\text { Proprioceptive } \\
\text { error (contralateral } \\
\text { dominant) }\end{array}$ & $\begin{array}{c}\text { Proprioceptive } \\
\text { error (contralateral } \\
\text { subdominant) }\end{array}$ \\
\hline $\begin{array}{c}\text { Body awareness } \\
\text { (SAS) }\end{array}$ & $-0.009 ; \mathrm{BF}_{10}=0.141$ & $0.037 ; \mathrm{BF}_{10}=0.230$ & $-0.008 ; \mathrm{BF}_{10}=0.143$ & $0.030 ; \mathrm{BF}_{10}=0.215$ \\
\hline $\begin{array}{c}\text { Body competence } \\
\text { (BCQ-PC) }\end{array}$ & $0.080 ; \mathrm{BF}_{10}=0.418$ & $-0.032 ; \mathrm{BF}_{10}=0.115$ & $0.068 ; \mathrm{BF}_{10}=0.349$ & $0.036 ; \mathrm{BF}_{10}=0.288$ \\
\hline $\begin{array}{c}\text { Positive affect } \\
\text { (PANAS-P) }\end{array}$ & $0.031 ; \mathrm{BF}_{10}=0.216$ & $0.003 ; \mathrm{BF}_{10}=0.159$ & $0.004 ; \mathrm{BF}_{10}=0.161$ & $-0.055 ; \mathrm{BF}_{10}=0.098$ \\
\hline $\begin{array}{c}\text { Negative affect } \\
\text { (PANAS-N) }\end{array}$ & $-0.023 ; \mathrm{BF}_{10}=0.197$ & $-0.061 ; \mathrm{BF}_{10}=0.317$ & $0.069 ; \mathrm{BF}_{10}=0.088$ & $0.187 ; \mathrm{BF}_{10}=0.047$ \\
\hline
\end{tabular}

One-tailed significance. SAS: Somatic Absorption Scale; BCQ-PC: Body Consciousness Scale - Physical Competence subscale; PANAS-P: Positive and Negative Affectivity Schedule - Positive Affectivity subscale; PANAS-N: Positive and Negative Affectivity Schedule - Negative Affectivity subscale; $\mathrm{BF}_{10}$ : Bayes factor.

Our findings do not support the existence of this relationship. According to previous studies that showed positive association between physical activity and proprioceptive acuity $(8,30)$, proprioception can be improved by physical activity, but apparently not by body-related attention.

Although proprioceptive accuracy is associated with physical performance in elite athletes $(11,14)$, we found no association between proprioceptive accuracy and perceived body competence in this study. The explanation might be the difference between the samples (elite athletes vs. sport-oriented university students), or that objective and subjective body competence may not completely overlap. The results show that proprioceptive acuity does not play a role in perceived physical competence.

According to our hypothesis, more accurate processing of proprioceptive signals is associated with more effective implementation of movements, which results in higher levels of self-efficacy and self-esteem (37), and in higher level of positive, and lower level of negative affect. In contrary to this assumption, we found no correlation between affect and proprioceptive acuity. However, empirical evidence indicates that the condition of the locomotor system has an important role in emotional processing. According to Cacioppo et al. (3), contraction of arm extensor muscles activates the avoidance system, as demonstrated by faster processing of negative words or more negative judgment of neutral stimuli, while the contraction of flexor muscles activates the approach system, which is associated with faster processing of positive words, or more positive judgment about neutral stimuli $(3,23)$. Our results show that proprioceptive acuity does not play such a relevant role in experiencing negative or positive emotions to make a trait-level difference between people in affectivity.

\section{Limitations}

In general, the proprioceptive acuity of the elbow joint does not necessarily represent a general proprioceptive ability, as proprioceptive accuracies measured in different joints do not correlate $(10,39)$.

Concerning the ecological validity of our findings, it is worth noting that the Joint Position Reproduction Test requires conscious effort, whereas proprioception and motor 
control work automatically most of the time (7). The two processes (i.e., conscious and automatic) might not completely overlap or relate. Empirical evidence also shows that bodyfocused attention has a negative impact on physical performance, presumably because of the disruption of automatic processes (43).

Low Cronbach's $\alpha$, measured in the half of the tasks, also represents a limitation of this study. It may be the result of proprioceptive acuity measured in the elbow joint being a nonunidimensional construct, as the accuracy can vary depending on the spatial position, and on the magnitude of the movement (8).

\section{Conclusion}

Although proprioception plays a fundamental role in motor performance and in psychological functioning, proprioceptive acuity, measured in the elbow joint, was not associated with perceived body awareness, body competence, and affectivity.

\section{Acknowledgements}

This research was supported by the Hungarian National Scientific Research Fund (KH 130319).

\section{REFERENCES}

1. Akyol Y, Ulus Y, Tander B, Bilgici A, Kuru O: Fibromiyaljili hastalarda kas gucu, yorgunluk, fonksiyonel kapasite ve proprioseptif keskinlik [Muscle strength, fatigue, functional capacity, and proprioceptive acuity in patients with fibromyalgia] (Online). Turk. J. Phys. Med. Rehabil. 59, 292-298 (2013)

2. Bardal EM, Roeleveld K, Ihlen E, Mork PJ: Micro movements of the upper limb in fibromyalgia: the relation to proprioceptive accuracy and visual feedback. J. Electromyogr. Kinesiol. 26, 1-7 (2016)

3. Cacioppo JT, Priester JR, Berntson GG: Rudimentary determinants of attitudes: II. Arm flexion and extension have differential effects on attitudes. J. Pers. Soc. Psychol. 65, 5-17 (1993)

4. Cameron M, Adams R, Maher C: Motor control and strength as predictors of hamstring injury in elite players of Australian football. Phys. Ther. Sport 4, 159-166 (2003)

5. Chang BP, Lenzenweger MF: Somatosensory processing and schizophrenia liability: proprioception, exteroceptive sensitivity, and graphesthesia performance in the biological relatives of schizophrenia patients. J. Abnorm. Psychol. 114, 85-95 (2005)

6. Faul F, Erdfelder E, Lang A-G, Buchner A: G*Power 3: a flexible statistical power analysis program for the social, behavioral, and biomedical sciences. Behav. Res. Methods 39, 175-191 (2007)

7. Gallagher S (2006): How the Body Shapes the Mind. Clarendon Press, Oxford, UK

8. Goble DJ: Proprioceptive acuity assessment via joint position matching: from basic science to general practice. Phys. Ther. 90, 1176-1184 (2010)

9. Gyollai Á, Simor P, Köteles F, Demetrovics Z: Psychometric properties of the Hungarian version of the original and the short form of the Positive and Negative Affect Schedule (PANAS). Neuropsychopharmacol. Hung. 13, 73-79 (2011)

10. Han J, Anson J, Waddington G, Adams R: Proprioceptive performance of bilateral upper and lower limb joints: side-general and site-specific effects. Exp. Brain Res. 226, 313-323 (2013)

11. Han J, Anson J, Waddington G, Adams R: Sport attainment and proprioception. Int. J. Sports Sci. Coach. 9 , 159-170 (2014)

12. Han J, Anson J, Waddington G, Adams R, Liu Y: The role of ankle proprioception for balance control in relation to sports performance and injury. Biomed Res. Int. 2015, 842804 (2015)

13. Han J, Waddington G, Adams R, Anson J, Liu Y: Assessing proprioception: a critical review of methods. J. Sport Health Sci. 5, 80-90 (2016)

14. Han J, Waddington G, Anson J, Adams R: Level of competitive success achieved by elite athletes and multi-joint proprioceptive ability. J. Sci. Med. Sport 18, 77-81 (2015) 
15. JASP Team: JASP (Version 0.9.0.1) [Computer software] (2018)

16. Jeannerod M: The mechanism of self-recognition in humans. Behav. Brain Res. 142, 1-15 (2003)

17. Kline RB (2013): Beyond Significance Testing. Statistics Reform in the Behavioral Sciences (2nd ed.). American Psychological Association, Washington, DC

18. Köteles F, Simor P, Tolnai N: Psychometric evaluation of the Hungarian version of the Somatic Absorption Scale. Mentálhigiéné és Pszichoszomatika 13, 375-395 (2012)

19. Leventhal DB, Schuck JR, Clemons JT, Cox M: Proprioception in schizophrenia. J. Nerv. Ment. Dis. 170, 21-26 (1982)

20. Lundberg U, Kadefors R, Melin B, Palmerud G, Hassmén P, Engström M, Elfsberg Dohns I: Psychophysiological stress and EMG activity of the trapezius muscle. Int. J. Behav. Med. 1, 354-370 (1994)

21. Miall RC, Wolpert DM: Forward models for physiological motor control. Neural Netw. 9, 1265-1279 (1996)

22. Miller LC, Murphy R, Buss AH: Consciousness of body: private and public. J. Pers. Soc. Psychol. 41, 397-406 (1981)

23. Neumann R, Strack F: Approach and avoidance: the influence of proprioceptive and exteroceptive cues on encoding of affective information. J. Pers. Soc. Psychol. 79, 39-48 (2000)

24. Parkhurst TM, Burnett CN: Injury and proprioception in the lower back. J. Orthop. Sports Phys. Ther. 19, 282-295 (1994)

25. Payne KA, Berg K, Latin RW: Ankle injuries and ankle strength, flexibility, and proprioception in college basketball players. J. Athl. Train. 32, 221-225 (1997)

26. Prochazka A (1996): Proprioceptive feedback and movement regulation. In: Handbook of Physiology. Section 12: Exercise: Regulation and Integration of Multiple Systems, eds, Rowell LB, Shepherd JT, American Physiological Society, New York, pp. 89-127

27. Proske U, Gandevia SC: The proprioceptive senses: their roles in signaling body shape, body position and movement, and muscle force. Physiol. Rev. 92, 1651-1697 (2012)

28. Ratcliffe N, Newport R: Evidence that subclinical somatoform dissociation is not characterised by heightened awareness of proprioceptive signals. Cogn. Neuropsychiatry 21, 429-446 (2016)

29. Rausch SM, Gramling SE, Auerbach SM: Effects of a single session of large-group meditation and progressive muscle relaxation training on stress reduction, reactivity, and recovery. Int. J. Stress Manag. 13, 273-290 (2006)

30. Ribeiro F, Oliveir J (2011): Factors influencing proprioception: what do they reveal? In: Biomechanics in Applications, ed Klika V, InTechOpen, London

31. Ritzler B, Rosenbaum G: Proprioception in schizophrenics and normals: effects of stimulus intensity and interstimulus interval. J. Abnorm. Psychol. 83, 106-111 (1974)

32. Ritzler BA: Proprioception and schizophrenia: a replication study with nonschizophrenic patient controls. J. Abnorm. Psychol. 86, 501-509 (1977)

33. Rosenbaum G, Cohen BD, Luby ED, Gottlieb JS, Yelen D: Comparison of sernyl with other drugs: simulation of schizophrenic performance with sernyl, LSD-25, and amobarbital (amytal) sodium; I. Attention, motor function, and proprioception. AMA Arch. Gen. Psychiatry 1, 651-656 (1959)

34. Rosenbaum G, Flenning F, Rosen H: Effects of weight intensity on discrimination thresholds of normals and schizophrenics. J. Abnorm. Psychol. 70, 446-450 (1965)

35. Scholz OB, Ott R, Sarnoch H: Proprioception in somatoform disorders. Behav. Res. Ther. 39, 1429-1438 (2001)

36. Sherrington C (1906): The Integrative Action of the Nervous System. Yale University Press, New Haven, CT

37. Sonstroem RJ, Morgan WP: Exercise and self-esteem: rationale and model. Med. Sci. Sports Exerc. 21, 329-337 (1989)

38. Ulus Y, Akyol Y, Tander B, Bilgici A, Kuru Ö: Fibromyalji Sendromu Tanısı Alan ve AlmayanTürk Kadınlarda Propriyosepsiyon ve Denge [Knee proprioception and balance in Turkish women with and without fibromyalgia syndrome]. Turk. J. Phys. Med. Rehabil. 59, 128-132 (2013)

39. Waddington G, Adams R: Ability to discriminate movements at the ankle and knee is joint specific. Percept. Mot. Skills 89, 1037-1041 (1999)

40. Watson D, Clark LA: Negative affectivity: the disposition to experience aversive emotional states. Psychol. Bull. 96, 465-490 (1984)

41. Watson D, Clark LA, Tellegen A: Development and validation of brief measures of positive and negative affect: the PANAS Scales. J. Pers. Soc. Psychol. 54, 1063-1070 (1988)

42. Wolpert DM, Flanagan JR: Motor prediction. Curr. Biol. 11, R729-R732 (2001)

43. Wulf G: Attentional focus and motor learning: a review of 15 years. Int. Rev. Sport Exerc. Psychol. 6, 77-104 (2013) 